\title{
Frontiers in green chemistry utilizing carbon dioxide for polymer synthesis and applications*
}

\author{
Jennifer L. Young and Joseph M. DeSimone \\ Department of Chemistry, Venable and Kenan Laboratories, University of North \\ Carolina, Chapel Hill, NC 27599-3290 USA
}

\begin{abstract}
In the last ten years, there has been incredible growth in research involving the use of carbon dioxide as an environmentally benign solvent. This article will highlight polymer synthesis, characterization, and applications in $\mathrm{CO}_{2}$ and place this research in the context of both green chemistry and the latest developments in $\mathrm{CO}_{2}$ technology.
\end{abstract}

\section{INTRODUCTION}

In recent years, the use of liquid and supercritical $\mathrm{CO}_{2}$ as a green, environmentally benign solvent for chemical reactions and polymerizations has become a widespread, growing reality, both in academia and in industry [1-5]. $\mathrm{CO}_{2}$ is a nontoxic, nonflammable, and inexpensive solvent. Although $\mathrm{CO}_{2}$ is a "greenhouse gas", $\mathrm{CO}_{2}$ can be acquired from natural reservoirs or recovered as a by-product of industrial chemical processes, so no new production of $\mathrm{CO}_{2}$ is necessary and there will be no additional contribution to the greenhouse gases. While $\mathrm{CO}_{2}$ is a gas at ambient conditions, its liquid and supercritical states are easily attained by compression and heat. The critical conditions of $31.1{ }^{\circ} \mathrm{C}$ and 73.8 bar are relatively low. Liquid $\mathrm{CO}_{2}$ is a compressible fluid, while supercritical $\mathrm{CO}_{2}$ has relatively high liquid-like densities and low gas-like viscosities. Both liquid and supercritical $\mathrm{CO}_{2}$ have a tuneable density (and dielectric constant) that increases with increasing pressure or decreasing temperature [6]. The solvency of supercritical $\mathrm{CO}_{2}$ is often compared to that of fluorocarbon solvents. Many small molecules are soluble in $\mathrm{CO}_{2}$ [7], including high vapor pressure solvents like methanol, acetone, and tetrahydrofuran, many vinyl monomers, and azo- and peroxy-initiators. Water and ionic compounds are insoluble [8,9], as are most polymers. Only two classes of polymers are soluble in $\mathrm{CO}_{2}$ at relatively mild conditions ( $\mathrm{T}<100{ }^{\circ} \mathrm{C}, \mathrm{P}<350 \mathrm{bar}$ ), amorphous or low-melting fluoropolymers and silicone-based polymers [10]. Herein, polymer synthesis, characterization, and applications in $\mathrm{CO}_{2}$ will be described, highlighting the environmental benefits of using $\mathrm{CO}_{2}$.

\section{POLYMER SYNTHESIS}

In $\mathrm{CO}_{2}$, few polymers, typically amorphous fluoropolymers, can be synthesized by a homogeneous, solution polymerization. Many insoluble polymers can be synthesized by a heterogeneous chain-growth process, such as precipitation, emulsion, dispersion, or suspension. Due to the solubility of many vinyl monomers and free-radical initiators in $\mathrm{CO}_{2}$ and the ability to design appropriate $\mathrm{CO}_{2}$-soluble polymeric surfactants, dispersion polymerization is a common heterogeneous polymerization method in $\mathrm{CO}_{2}$. Stepgrowth polymerizations can also be conducted in $\mathrm{CO}_{2}$ with advantages over other processes. Most of the polymers synthesized in $\mathrm{CO}_{2}$ to date can be classified into three categories: fluoropolymers, dispersion polymers, and step-growth polymers.

*Pure Appl. Chem. Vol. 72, No. 7, 2000. A special topic issue on green chemistry. 


\section{Fluoropolymers}

Fluoropolymer synthesis in $\mathrm{CO}_{2}$, which is the subject of a recent chapter review [11], will now be discussed in the context of green chemistry. The synthesis of fluoropolymers in $\mathrm{CO}_{2}$ is environmentally advantageous since these polymers are typically prepared in chlorofluorocarbons (CFCs) and other fluorinated solvents as well as in water. The association of CFCs with ozone layer destruction and the environmentally harmful nature and expense of fluorinated solvents necessitate the search for replacement solvents. Many fluoropolymerizations cannot be conducted in hydrocarbon solvents because of the detrimental side reactions arising from radical abstraction of hydrogen atoms from the solvent. Since $\mathrm{CO}_{2}$ has no hydrogens to abstract, there is no chain transfer to $\mathrm{CO}_{2}$. Amorphous fluoropolymers, such as highly fluorinated (meth)acrylates and perfluoropolyethers, are highly soluble in $\mathrm{CO}_{2}$ and have been synthesized by solution polymerizations in supercritical $\mathrm{CO}_{2}[12,13]$. Low-molecular-weight oligomers of poly(tetrafluoroethylene) (PTFE) and poly(1,1-difluoroethylene) (PVDF), which remain soluble in $\mathrm{CO}_{2}$ below a limiting molecular weight, have been synthesized by telomerizations in $\mathrm{CO}_{2}[14,15]$. Semicrystalline, high-melting-temperature fluoropolymers, such as PTFE and PVDF, are insoluble in $\mathrm{CO}_{2}$ due to their crystallinity and are polymerized by various heterogeneous methods in $\mathrm{CO}_{2}$ [16-18].

Fluorinated acrylate polymers have been synthesized by homogeneous, solution polymerizations in $\mathrm{CO}_{2}$ [12]. Using azobis(isobutyronitrile) (AIBN) as the thermal free-radical initiator, 1,1dihydroperfluorooctyl acrylate (FOA) was polymerized at $60{ }^{\circ} \mathrm{C}, 207$ bar. The high-molecular-weight polymer, PFOA, remained soluble in supercritical $\mathrm{CO}_{2}$ and was identical to that polymerized in a CFC. It was also shown that statistical copolymers containing FOA and either methyl methacrylate, styrene, butyl acrylate, or ethylene, could be polymerized under homogeneous, solution polymerization conditions in $\mathrm{CO}_{2}$. PFOA and $\mathrm{CO}_{2}$-soluble copolymers containing PFOA are useful polymeric surfactants for applications including dispersion polymerizations and extractions, as will be shown later in this review.

Perfluoropolyethers, which find applications as high-performance lubricants and heat-transfer fluids, constitute another class of fluoropolymers that have been synthesized in $\mathrm{CO}_{2}$ [13]. The photooxidation of hexafluoropropylene (HFP) was performed in liquid $\mathrm{CO}_{2}$ at $-40^{\circ} \mathrm{C}$ to yield perfluoropolyethers soluble in $\mathrm{CO}_{2}$. This study showed that $\mathrm{CO}_{2}$ is a viable solvent replacement for the dichlorodifluoromethane currently used in some commercial fluoroolefin photooxidations.

Tetrafluoroethylene (TFE) polymerizations in $\mathrm{CO}_{2}$ are sensible because this dangerous, potentially explosive monomer is safely stored and handled as a pseudo-azeotrope with $\mathrm{CO}_{2}[19,20]$. Copolymerizations of TFE with perfluoro(propyl vinyl ether) (PPVE) or HFP in $\mathrm{CO}_{2}$ have produced polymers with levels of comonomer incorporation similar to commercial polymers [16]. The TFE-PPVE copolymers also contained an unprecedented $0-3$ acid endgroups per $10^{6}$ carbon atoms, which are comparable to copolymers synthesized in CFCs and treated with a harsh fluorination process. TFE was also polymerized to high molecular weights in a biphasic mixture of $\mathrm{CO}_{2}$ and water by heterogeneous methods similar to the industrial suspension and dispersion processes [17]. Using a persulfate initiator in the absence of a surfactant, aggregates with diameters of $0.5-3 \mu \mathrm{m}$ were produced and resemble the granular PTFE formed commercially by suspension polymerization in water. In the presence of a $\mathrm{CO}_{2}$ soluble surfactant, particles with diameters of 100-200 nm were produced and are similar to those made commercially by conventional aqueous dispersion polymerization.

In the first continuous polymerizations in $\mathrm{CO}_{2}$ reported recently [18], PVDF and poly(acrylic acid) were produced by continuous precipitation polymerization. A continuous polymerization process is much more commercially and environmentally viable than a batch polymerization, producing a larger amount of polymer in a given amount of time. The PVDF was formed at $75^{\circ} \mathrm{C}, 275$ bar and collected in a filter after polymerization residence times of between 15 and $40 \mathrm{~min}$ in the continuous stirred tank reactor.

(C) 2000 IUPAC, Pure and Applied Chemistry 72, 1357-1363 


\section{Dispersion polymers}

$\mathrm{CO}_{2}$ is well suited as a reaction medium for dispersion polymerizations because many vinyl monomers and polymerization initiators are soluble in $\mathrm{CO}_{2}$ while the polymers formed are insoluble [1,21]. Surfactants for steric stabilization of the colloidal polymer particles in $\mathrm{CO}_{2}$ must be soluble and must adsorb or chemically graft to the polymer particles and can consist of homopolymers, block, graft, and random copolymers, and reactive macromonomers. Polymer latexes produced in $\mathrm{CO}_{2}$ eliminate volatile organic compound (VOC) emissions and can significantly reduce the energy-intensive drying process since $\mathrm{CO}_{2}$ has a heat of vaporization which is low in the liquid state and zero in the supercritical state. Furthermore, polymer can be shipped dry as $100 \%$ solids and later be redispersed to save energy and money in shipping rather than shipping a heavy water latex.

Initial studies illustrated the dispersion polymerization of methyl methacrylate (MMA) using PFOA as the stabilizer $[22,23]$. The next study of MMA dispersion polymerizations focused on the use of another class of surfactants, based on poly(dimethyl siloxane) (PDMS), which are less expensive than fluoropolymer-based surfactants [24]. Initial attempts of styrene dispersion polymerizations in $\mathrm{CO}_{2}$ with PFOA and PDMS homopolymer stabilizers gave low yields and latex instability, but the block copolymers PS- $b$-PFOA and PS- $b$-PDMS produced submicron-sized PS particles [25,26]. Block copolymer surfactants containing poly(vinyl acetate) (PVAc), PVAc- $b$-PDMS and PVAc- $b$-PFOA, were effective stabilizers for dispersion polymerizations of vinyl acetate and copolymerizations of vinyl acetate and ethylene [27]. These dispersion polymerizations are summarized more extensively in a recent review with other examples [1].

Recently, PFOA and its methacrylate analog PFOMA were found to be effective stabilizers for PS at higher $\mathrm{CO}_{2}$ pressures (370 bar) [28] while PFOA was ineffective at lower pressures of 204 bar [25]. Random copolymers, PS-co-PFOMA and PS-co-TMSOSPMA (3-[tris(trimethylsilyloxy)silyl]propyl methacrylate), are also effective stabilizers, producing micron-sized PS particles [29]. Such random copolymer surfactants, which can be prepared by a free-radical polymerization, are easier to synthesize than block copolymer surfactants, which must be prepared by "controlled" radical polymerization or living anionic polymerization. Recently, several other monomers have been polymerized by dispersion polymerizations, including 1-vinyl-2-pyrrolidone [30], acrylonitrile [31], hydroxyethyl methacrylate [32], and glycidyl methacrylate [33]. These examples extend the dispersion polymerizations into watersoluble, polar polymers and functionalized polymers.

A new concept for the preparation of water-dispersible polymer particles in $\mathrm{CO}_{2}$ has been developed by Johnston [34]. PMMA was synthesized in $\mathrm{CO}_{2}$ using an "ambidextrous" surfactant. The surfactant contains a water-soluble polymer block that anchors to the particle in $\mathrm{CO}_{2}$ but becomes the electrostatic stabilizer in water and a PDMS block that is the steric stabilizer in $\mathrm{CO}_{2}$ but collapses and anchors to the particle in water. The PDMS- $b$-poly(methacrylic acid) surfactant was less effective during the dispersion polymerization of MMA in $\mathrm{CO}_{2}$, but up to $10 \mathrm{wt} \%$ of the PMMA particles formed could be redispersed in water at $\mathrm{pH} 8$ or 11. The other surfactant, PDMS- $g$-poly(pyrrolidonecarboxylic acid) was more effective during the dispersion polymerization, but the PMMA particles formed could not be redispersed in water.

A recent report demonstrates the synthesis of highly cross-linked polymer particles in supercritical $\mathrm{CO}_{2}$ [35]. Even in the absence of a stabilizer, the polymerization of divinylbenzene and ethylvinylbenzene produced polymer particles $1-5 \mu \mathrm{m}$ in diameter. Addition of a block copolymer containing PMMA and a fluorinated polymethacrylate produced submicron-sized, monodisperse particles. Two other crosslinking monomers, ethylene glycol dimethacrylate (EGDM) and trimethylolpropane trimethacrylate (TRM) formed agglomerates of particles when polymerized in the absence of a stabilizer. At higher EGDM and TRM monomer concentrations (40-60\%), continuous macroporous polymer monoliths were produced and pore diameters could be varied from 7880 to $20 \mathrm{~nm}$ by varying the monomer concentration and $\mathrm{CO}_{2}$ pressure [36].

(C) 2000 IUPAC, Pure and Applied Chemistry 72, 1357-1363 
The chain-growth polymerizations discussed so far in this paper have been free-radical polymerizations, typically initiated by AIBN. Using "controlled" free-radical polymerization techniques, such as atom transfer radical polymerization (ATRP), it is possible to obtain polymer chains with a very narrow molecular weight distribution and to synthesize block copolymers. Using $\mathrm{Cu}(0), \mathrm{CuCl}, \mathrm{a}$ functionalized bipyridine ligand, and an alkyl halide initiator, the block copolymers containing PMMA or PDMAEMA (DMAEMA = 2-(dimethylamino)ethyl methacrylate) were synthesized in $\mathrm{CO}_{2}$ [37]. Also in this report the dispersion polymerization in $\mathrm{CO}_{2}$ of MMA with PFOA as the stabilizer was conducted by ATRP. The resulting PMMA had a relatively narrow molecular weight distribution $\left(\mathrm{M}_{\mathrm{w}} /\right.$ $\left.M_{n}=1.4\right)$ in comparison to the same dispersion polymerization initiated by AIBN $\left(M_{w} / M_{n}=2-3\right)$ [23].

\section{Step-growth polymers}

The recent advances in step-growth polymerizations in $\mathrm{CO}_{2}$ have focused on poly(bisphenol A carbonate). One of the two primary industrial methods for polycarbonate synthesis uses methylene chloride, which is environmentally unfriendly, and phosgene, which is highly toxic. The other method, melt-phase polymerization, uses no solvent, but is limited by the high polymer melt viscosities and the high temperatures necessary for polymerization and processing. The presence of $\mathrm{CO}_{2}$ in a melt polymerization plasticizes the polymer and reduces the viscosity, so the condensate can be removed more easily and

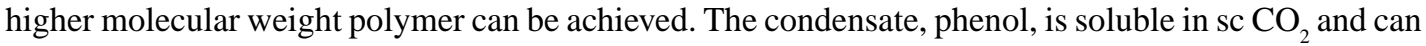
be efficiently extracted from the polymer by supercritical fluid extraction. Low-molecular-weight polycarbonate was shown to swell up to $55 \%$ at $235^{\circ} \mathrm{C}, 350$ bar [38]. Also, in this study, bisphenol A and diphenyl carbonate were polymerized to produce molecular weights up to $13 \mathrm{~kg} / \mathrm{mol}$. Under each reaction conditions, higher molecular weights were achieved by sc $\mathrm{CO}_{2}$ extraction as opposed to phenol removal by argon.

Solid-state polymerization of polycarbonate has also been studied using sc $\mathrm{CO}_{2}$ to crystallize the polymer and to remove the phenol condensate $[39,40]$. In a solid-state polymerization, low-molecularweight, semi-crystalline step-growth polymer beads are heated between the polymer $\mathrm{Tg}$ and $\mathrm{Tm}$ to allow for condensate and chain mobility for further chain extension reactions. Following the crystallization of beads of low-molecular-weight polycarbonate prepolymer by sc $\mathrm{CO}_{2}$, solid-state polymerizations were conducted. The polymerization rates in the solid state were found to be always greater with condensate removal facilitated by sc $\mathrm{CO}_{2}$ as opposed to nitrogen under comparable conditions. Also, since the $\mathrm{Tg}$ of polycarbonate is decreased by over $70^{\circ} \mathrm{C}$ in the presence of $\mathrm{sc}^{\mathrm{CO}}$, the polymerization can be run at much lower temperatures, saving energy and suppressing the side reactions that lead to unwanted polymer discoloration.

\section{CHARACTERIZATION}

In order to study polymers and polymerization mechanisms in $\mathrm{sc}^{\mathrm{CO}}$, analytical techniques have been modified for high pressure. Methods including IR, UV-vis, and NMR spectroscopies and scattering techniques are now possible at high pressures. This paper will focus on scattering techniques, including small-angle neutron scattering (SANS), small-angle X-ray scattering (SAXS), and light scattering.

Both SANS and SAXS are powerful tools for determining the polymer radius of gyration, the second virial coefficient, $\mathrm{A}_{2}$, which indicates the solvent quality for the polymer, and block copolymer micelle formation. SANS studies have shown that $\mathrm{CO}_{2}$ is a good solvent for PFOA, a theta solvent for poly(hexafluoropropylene oxide), and a poor solvent for PDMS [41,42]. More recently, SANS research has shown a temperature- and pressure-induced theta point for PDMS in $\mathrm{CO}_{2}$ [43]. At conditions above the theta point, $\mathrm{CO}_{2}$ becomes a good solvent for PDMS. The aggregation behavior of three different amphiphiles in $\mathrm{CO}_{2}$ was studied by SAXS [44]. The graft copolymer with a PFOA backbone and poly(ethylene oxide) (PEO) grafts formed micelles which stabilized water in $\mathrm{CO}_{2}$, while the PTFE- $b$ PEO copolymer formed reverse micelles, and $\mathrm{F}\left(\mathrm{CF}_{2}\right)_{10}\left(\mathrm{CH}_{2}\right)_{10} \mathrm{H}$ formed small aggregates of at most 
four chains. The block copolymer PS- $b$-PFOA forms micelles in $\mathrm{CO}_{2}$ with a PS core and a PFOA shell and the data fits a polydisperse spherical core-shell model $[45,46]$. With an increase in $\mathrm{CO}_{2}$ density, the change in polydispersity suggests the existence of a critical micelle density, or a density of $\mathrm{CO}_{2}$ above which the micelles are broken up into soluble unimers.

High pressure static and dynamic light scattering were used to confirm the existence of a critical micelle density for block copolymers of PVAc and poly(1,1,2,2-tetrahydroperfluoroalkyl acrylate) (PTAN) [47]. The block copolymer is insoluble at low $\mathrm{CO}_{2}$ densities, forms spherical micelles at intermediate densities, and exists as unimers, or free polymer chains in solution, at high $\mathrm{CO}_{2}$ densities. The transition of micelles-to-unimers was found to be very sharp, with the aggregation number decreasing from 120 to 1 with an increase in density.

The in situ analysis of dispersion polymerizations in $\mathrm{CO}_{2}$ has provided insight into the mechanism of the polymerizations. Turbidimetry, tensiometry, and dynamic light scattering confirmed that the critical flocculation density occurred at the theta point of the surfactant for poly(2-ethylhexyl acrylate) dispersed and sterically stabilized in $\mathrm{CO}_{2}[48,49]$. Turbidimetry was also used to study the dispersion polymerizations of vinyl acetate [27]. This in situ technique for measuring the polymer particle size is particularly useful since the PVAc particle shape is lost during the removal of $\mathrm{CO}_{2}$ due to the low Tg of the polymer. The dispersion polymerization of MMA stabilized by PDMS-monomethacrylate has also been the subject of mechanistic investigations [50,51]. The particle formation mechanism, studied by turbidimetry, involved coagulative nucleation and controlled coagulation [51]. The results obtained during the particle formation and particle growth stages agreed with the previous experimental study of Shaffer et al. [24].

\section{APPLICATIONS AND OUTLOOK}

With the design of specific polymers as surfactants for $\mathrm{CO}_{2}$, numerous environmentally benign applications for this clean, green solvent can be realized, of which extractions, cleaning, and coatings are just a few examples. For extractions and cleaning, the surfactant acts as a detergent to bring the insoluble species or contaminant into the $\mathrm{CO}_{2}$ phase. Depressurization of the $\mathrm{CO}_{2}$ or changing the $\mathrm{CO}_{2}$ density will cause the contaminant to be released from the surfactant. For example, a block copolymer was used to extract deuterated oligomers into $\mathrm{CO}_{2}$ [45], and a dendrimer was used to extract a water soluble, $\mathrm{CO}_{2}$-insoluble dye from the water phase into the $\mathrm{CO}_{2}$ phase [52]. Detergents for $\mathrm{CO}_{2}$ can be used for cleaning applications, such as "dry cleaning" using liquid $\mathrm{CO}_{2}$ as the solvent instead of the common perchloroethylene, a probable human carcinogen [53]. In coating, the polymer to be delivered from the $\mathrm{CO}_{2}$ can be soluble, such as a fluoropolymer, or an insoluble dispersed species. The application of coatings from $\mathrm{CO}_{2}$ has been demonstrated by three different methods, including spray, spin, and freemeniscus coating, and extends $\mathrm{CO}_{2}$ into areas such as microlithography, hard disk lubrication, and protective coatings [54]. Clearly, $\mathrm{CO}_{2}$ can be used widely as an environmentally benign solvent for polymer synthesis and for numerous polymer-based applications.

\section{REFERENCES}

1. J. L. Kendall, D. A. Canelas, J. L.Young, J. M. DeSimone. Chem. Rev. 99, 543-563 (1999).

2. P. G. Jessop and W. Leitner. Chemical Synthesis Using Supercritical Fluids, Wiley-VCH, Weinheim; Chichester (1999).

3. W. Leitner. In Modern Solvents in Organic Chemistry, pp 107-132, Springer-Verlag, Berlin (1999).

4. A. I. Cooper. J. Mater. Chem. 10, 207-234 (2000).

5. J. M. DeSimone, W. Tumas, J. L. Young, P. A. Anastas. Green Chemistry Using Liquid and Supercritical Carbon Dioxide, Oxford University Press, Oxford, submitted for publication (2000).

6. F. G. Keyes and J. G. Kirkwood. Phys. Rev. 36, 754 (1930).

(C) 2000 IUPAC, Pure and Applied Chemistry 72, 1357-1363 
7. J. A. Hyatt. J. Org. Chem. 49, 5097-5101 (1984).

8. H. H. Lowry and W. R. Erickson. J. Am. Chem. Soc. 49, 2729 (1927).

9. M. B. King, A. Mubarak, J. D. Kim, T. R. Bott. J. Supercrit. Fluids 5, 296 (1992).

10. M. A. McHugh and V. J. Krukonis. Supercritical Fluids Extraction: Principles and Practice; 2nd ed.; Butterworth-Heinemann, Boston (1994).

11. J. P. DeYoung, T. J. Romack, J. M. DeSimone. In Fluoropolymers 1: Synthesis, Hougham, et. al., (Eds.), pp 191-205. Plenum Press, New York (1999).

12. J. M. DeSimone, Z. Guan, C. S. Eisbernd. Science 257, 945-947 (1992).

13. W. C. Bunyard, T. J. Romack, J. M. DeSimone. Macromolecules, 32 8224-8226 (1999).

14. T. J. Romack, J. R. Combes, J. M. DeSimone. Macromolecules 28, 1724-1726 (1995).

15. J. R. Combes, Z. Guan, J. M. DeSimone. Macromolecules 27, 865-867 (1994).

16. T. J. Romack, J. M. DeSimone, T. A. Treat. Macromolecules 28, 8429-8431 (1995).

17. T. J. Romack, B. E. Kipp, J. M. DeSimone. Macromolecules 28, 8432-8434 (1995).

18. P. A. Charpentier, K. A. Kennedy, J. M. DeSimone, G. W. Roberts. Macromolecules 32, 59735975 (1999).

19. S. V. Gangal. In Encyclopedia of Polymer Science and Engineering, p 577. Wiley-Interscience, New York (1988).

20. D. J. Van Bramer, M. B. Shiflett, A.Yokozeki. U.S. Patent 5345 013, 1994.

21. D. A. Canelas and J. M. DeSimone. Adv. Polym. Sci. 133, 103-140 (1997).

22. J. M. DeSimone, E. E. Maury, Y. Z. Menceloglu, J. B. McClain, T. R. Romack, J. R. Combes. Science 265, 356-359 (1994).

23. Y.-L. Hsiao, E. E. Maury, J. M. DeSimone, S. M. Mawson, K. P. Johnston. Macromolecules 28, 8159-8166 (1995).

24. K. A. Shaffer, T. A. Jones, D. A. Canelas, J. M. DeSimone, S. P. Wilkinson. Macromolecules 29, 2704-2706 (1996).

25. D. A. Canelas, D. E. Betts, J. M. DeSimone. Macromolecules 29, 2818-2821 (1996).

26. D. A. Canelas and J. M. DeSimone. Macromolecules 30, 5673-5682 (1997).

27. D. A. Canelas, D. E. Betts, J. M. DeSimone, M. Z. Yates, K. P. Johnston. Macromolecules 31, 6794-6805 (1998).

28. H. Shiho and J. M. DeSimone. J. Polym. Sci. Part A: Polym. Chem. 37, 2429-2437 (1999).

29. H. Shiho and J. M. DeSimone. J. Polym. Sci. Part A: Polym. Chem. 38, 1146-1153 (2000).

30. T. Carson, J. Lizotte, J. M. DeSimone. Macromolecules 33, 1917-1920 (2000).

31. H. S. Shiho and J. M. DeSimone. Macromolecules 33, 1565-1569 (2000).

32. H. Shiho and J. M. DeSimone. J. Polym. Sci. Part A: Polym. Chem., submitted (2000).

33. H.Shiho and J. M. DeSimone. Macromolecules, submitted (2000).

34. M. Z. Yates, G. Li, J. J. Shim, S. Maniar, K. P. Johnston, K. T. Lim, S. Webber. Macromolecules 32, 1018-1026 (1999).

35. A. I. Cooper, W. P. Hems, A. B. Holmes. Macromolecules 32, 2156-2166 (1999).

36. A. I. Cooper and A. B. Holmes. Adv. Mater. 11, 1270 (1999).

37. J. H. Xia, T. Johnson, S. G. Gaynor, K. Matyjaszewski, J. DeSimone. Macromolecules 32, 4802 4805 (1999).

38. S. M. Gross, R. D. Givens, M. Jikei, J. R. Royer, S. Khan, J. M. DeSimone, P. G. Odell, G. K. Hamer. Macromolecules 31, 9090-9092 (1998).

39. S. M. Gross, D. Flowers, G. Roberts, D. J. Kiserow, J. M. DeSimone. Macromolecules 32, $3167-$ 3169 (1999).

40. S. M. Gross, G. W. Roberts, D. J. Kiserow, J. M. DeSimone. Macromolecules 33, 40-45 (2000). 
41. J. B. McClain, D. Londono, J. R. Combes, T. J. Romack, D. A. Canelas, D. E. Betts, G. D. Wignall, E. T. Samulski, J. M. DeSimone. J. Am. Chem. Soc. 118, 917-918 (1996).

42. D. Chillura-Martino, R. Triolo, J. B. McClain, J. R. Combes, D. E. Betts, D. A. Canelas, E. T. Samulski, J. M. DeSimone, H. D. Cochran, J. D. Londono, G. D. Wignall J. Mol. Struct. 383, $3-$ 10 (1996).

43. Y. B. Melnichenko, E. Kiran, G. D. Wignall, K. D. Heath, S. Salaniwal, H. D. Cochran, M. Stamm. Macromolecules 32, 5344-5347 (1999).

44. J. L. Fulton, D. M. Pfund, J. B. McClain, T. J. Romack, E. E. Maury, J. R. Combes, E. T. Samulski, J. M. DeSimone, M. Capel. Langmuir 11, 4241-4249 (1995).

45. J. B. McClain, D. E. Betts, D. A. Canelas, E. T. Samulski, J. M. DeSimone, J. D. Londono, H. D. Cochran, G. D. Wignall, D. Chillura-Martino, R. Triolo. Science 274, 2049-2052 (1996).

46. J. D. Londono, R. Dharmapurikar, H. D. Cochran, G. D. Wignall, J. B. McClain, D. E. Betts, D. A. Canelas, J. M. DeSimone, E. T. Samulski, D. Chillura-Martino, R. Triolo. J. Appl. Crystallogr. 30, 690-695 (1997).

47. E. Buhler, A. V. Dobrynin, J. M. DeSimone, M. Rubinstein. Macromolecules 31, 7347-7355 (1998).

48. M. L. O’Neill, M. Z. Yates, K. L. Harrison, K. P. Johnston, D. A. Canelas, D. E. Betts, J. M. DeSimone, S. P. Wilkinson. Macromolecules 30, 5050-5059 (1997).

49. M. Z. Yates, M. L. O'Neill, K. P. Johnston, S. Webber, D. A. Canelas, D. E. Betts, J. M. DeSimone. Macromolecules 30, 5060-5067 (1997).

50. M. L. O'Neill, M. Z. Yates, K. P. Johnston, C. D. Smith, S. P. Wilkinson. Macromolecules 31, 2838-2847 (1998).

51. M. L. O'Neill, M. Z. Yates, K. P. Johnston, C. D. Smith, S. P. Wilkinson. Macromolecules 31, 2848-2856 (1998).

52. A. I. Cooper, J. D. Londono, G. Wignall, J. B. McClain, E. T. Samulski, J. S. Lin, A. Dobrynin, M. Rubinstein, A. L. C. Burke, J. M. J. Fréchet, J. M. DeSimone. Nature 389, 368 (1997).

53. G. Stewart. In Green Chemistry Using Liquid and Supercritical Carbon Dioxide, J. M. DeSimone, W. Tumas, J. L. Young, and P. A. Anastas, (Eds.), Oxford University Press, Oxford, submitted for publication (2000).

54. Y. Chernyak, F. Henon, E. Hoggan, B. Novick, J. DeSimone, R. Carbonell. In Green Chemistry Using Liquid and Supercritical Carbon Dioxide, J. M. DeSimone, W. Tumas, J. L. Young, P. A. Anastas (Eds.), Oxford University Press, Oxford, submitted for publication (2000).

(C) 2000 IUPAC, Pure and Applied Chemistry 72, 1357-1363 